\title{
Modifications to Johanson's Roll Compaction Model for Improved Relative Density Predictions
}

Yu Liu and Carl Wassgren ${ }^{\mathrm{a}, \mathrm{b}, *}$

${ }^{a}$ School of Mechanical Engineering, 585 Purdue Mall, Purdue University, West Lafayette, IN 47907-2088, U.S.A.

${ }^{\mathrm{b}}$ Department of Industrial and Physical Pharmacy (by courtesy), 575 Stadium Mall Drive, Purdue University, West Lafayette, IN 47907-2091, U.S.A.

* Corresponding author at: School of Mechanical Engineering, Purdue University, West Lafayette, IN 47907-2088, U.S.A., Tel.: +1 765494 5656, E-mail address: wassgren@purdue.edu (C. Wassgren).

Keywords: Roll compaction; Johanson's model; Finite element method

\begin{abstract}
Johanson's roll compaction model [J.R. Johanson, A rolling theory for granular solids, ASME Journal of Applied Mechanics E32 (1965) 842-848] is modified to improve its predictions of a compacted ribbon's relative density. Previous work has shown that the maximum roll pressure and ribbon relative density predicted by the Johanson model are not only larger than those predicted from finite element method (FEM) simulations, but also unphysical in some cases. This over-prediction is due to a one-dimensional flow assumption in the Johanson model. Real powder velocity profiles within a roll compactor are non-uniform. Johanson's analysis is modified in this work to include a mass correction factor to account for the improper one-dimensional flow assumption, similar to what was proposed by Bi et al. [M. Bi, F. Alvarez-Nunez, F. Alvarez, Evaluating and modifying Johanson's rolling model to improve its predictability, J Pharm Sci. 103 (2014) 2062-2071]. Unlike Bi et al.’s work, however, an empirical curve fit accounting for the mass correction factor's dependence on position is included in the current analysis. The fit has two fitting parameters, which can be determined from online measurements. Predictions of the average relative density at the minimum gap width from the modified Johanson model are compared to predictions from twodimensional FEM models and the errors are found to be approximately 5\% larger than the FEM predictions. The unmodified Johanson model over-predicts the FEM results by around 50\%. Comparisons to published experimental
\end{abstract}


data also show good agreement. This modified Johanson model can be used in control schemes to provide much better estimates of ribbon relative density in roll compaction operations.

\section{$1 \quad$ Introduction}

Roll compaction is a widely used unit operation during the production of powder-based products in the pharmaceutical, chemical, consumer products, ceramics, and food industries. Roll compaction is a dry granulation process in which loose powder is compressed to produce a continuous, compacted ribbon with non-zero porosity. The resulting ribbon is typically processed further, for example by milling into granules, blending with other materials, and compacting into tablets.

A roll compaction parameter of particular interest is the resulting ribbon's bulk density distribution. Most other ribbon properties, such as elastic modulus, Poisson's ratio, and fracture strength, are functions of the bulk density. In addition, since the ribbon is usually milled into granules, the granule distribution properties are strong functions of the ribbon properties. These granule properties are known to have significant influence on the resulting product properties, such as disintegration and compact strength [1]. Thus, having the ability to predict and control the ribbon bulk density distribution is of significant interest.

Although roll compaction has been used extensively within industry, the process is still often designed using empirical methods. Design of experiments (DOE) approaches are not uncommon despite a number of mechanistic models for the process being available since the 1960s. The one-dimensional model of Johanson [2] is perhaps the most commonly cited roll compaction model, but the "slab" method [3] has also been proposed. Computational finite element method (FEM) models for roll compaction [4-8] are becoming more common and can provide extensive information on the powder state, but at the expense of increased complexity and calculation time. The reliance on empirical studies may be due in part to the inaccuracy of one-dimensional model predictions, which is discussed in greater detail in the following sections, and the effort and experience needed to implement an FEM model. 
The current work focuses on improving the prediction of the average ribbon relative density from the Johanson model [2]. An approach to correct for the one-dimensional flow assumption made by Johanson is included in the ribbon relative density analysis. Predictions from this modified model are compared to FEM simulation results and published experimental data.

\section{$2 \quad$ Background}

Although other roll compaction mechanistic modeling approaches have been proposed, the Johanson model [2] is the most commonly used one and, hence, is the focus of the current study. The model is one-dimensional and does not require significant computational resources; hence, it is ideal for initial design calculations and control schemes. At the other end of the computational spectrum are finite element method (FEM) models, which can be multidimensional and provide detailed powder state information, but at the expense of increased model development and computational effort. The remainder of this section gives a general description of the Johanson model along with comparisons to FEM simulations and experimental measurements.

Details of the Johanson model derivation are provided in Section 4, but it is worthwhile to state here the major assumptions of the model and its capabilities. The roll geometry is assumed known, which is reasonable. The stress at the inlet to the slip region is also assumed known, but this is generally not true in practice. Little effort has been invested into predicting this inlet stress, although there has been recent work [9] relating the torque of a feed screw leading into the rolls to the inlet stress. The powder in the model was assumed by Johanson to be isotropic, frictional, cohesive, compressible, and obey the Jenike-Shield yield criterion [10]. Johanson further proposed that the powder's relative density is related to the applied stress via a power law relationship, which fits experimental measurements [11]. Additional powder properties used in the model include the effective angle of internal friction and the powder-roll friction angle, both of which are assumed constant with relative density, which is reasonable at the large stresses expected in a roll compactor [5].

Johanson assumed that powder flow through the roll compactor is one-dimensional, with a speed less than the roll speed in the upstream "slip" region and equal to the roll speed in the downstream "no-slip" region. The transition between regions occurs at the "nip" angle, which is calculated in the Johanson model by equating powder stress 
gradients in the two different regions. Once in the no-slip region, the powder relative density is found through simple geometry and the corresponding applied stress is determined using the aforementioned power law constitutive relationship. In addition to the nip angle, the Johanson model can be used to predict the final ribbon relative density at the minimum gap and the force and torque acting on the rolls.

Several experimental studies have attempted to validate the Johanson model. For example, Bindhumadhavan et al. [12] found that the predicted nip angle agreed with experimental measurements to within $15 \%$. Recent work by Krok et al. [13] shows that during roll compaction, the powder behavior is dynamic and the influence of the rolls may only be observed in a thin layer that is in contact with the roll surfaces. Hence, the nip angle may not be a single value across the thickness of the ribbon. Yusof et al. [14] also noted reasonable agreement between experiments and model predictions of the roll force, but only for roll gaps smaller than $0.15 \mathrm{~mm}$. The latter authors also noted that a slight change in the initial bulk porosity had a large effect on the calculated roll force, which did not agree with experiment results.

Recent two-dimensional FEM simulation studies by Muliadi et al. [5] found that the Johanson model produces reasonable nip angle predictions. However, the Johanson model over-predicts the maximum roll pressure and ribbon relative density significantly, and in many cases predicts relative densities greater than one, which is non-physical. The cause for the poor relative density predictions was because powder flow through the roll compactor is not onedimensional. Indeed, the powder speed in the no-slip region is fastest at the rolls and slowest at the centerline. Similar observations were made in the FEM studies by Cunningham [7] and Zavaliangos et al. [15], and in the experiments by Orowan [16]. As noted by Muliadi et al. [5], because Johanson assumes one-dimensional flow with a speed equal to the roll speed, the mass flow rate through the system is larger than what actually occurs. As a result, the ribbon relative density is over-predicted.

The objective of the current work is to improve the ribbon relative density predictions of the Johanson model by modifying its analysis to correct for the assumption of one-dimensional flow. The approach used here is similar to the one proposed recently by Bi et al. [17], who make use of a mass correction factor. The implementation here, however, is different and is described in detail in Section 4. Section 5 compares the modified Johanson model 
predictions to FEM simulation results and published experimental data. Details of these FEM models are given in the following section.

\section{$3 \quad$ Finite Element Method Model}

A two-dimensional FEM model is used here to provide: (a) insights into the form of the mass correction factor relation described in Section 4, and (b) a means of validation, albeit a computational one rather than an experimental one. Note that model comparisons to experimental measures are provided in Section 5. Prior studies [6-8] have shown that FEM models can provide good predictions of the ribbon relative density.

The FEM model used here is derived from the one described by Muliadi et al. [5]. For convenience, several aspects of this model are presented here. The commercial FEM package Abaqus/Explicit V6.14 is used to perform the simulations. The system geometry is shown in Fig. 1 and mimics an Alexanderwerks Model WP 200 PHARMA labscale roll compactor with $200 \mathrm{~mm}$ diameter rollers and a minimum gap width of up to $5 \mathrm{~mm}$. Gravity is not included in the model. The roll and inlet channel boundaries are assumed to be non-deformable, frictional, Lagrangian boundaries while the lower boundary is a plane of symmetry. Eulerian boundary conditions are used at the inlet and outlet so that material can flow continuously through the domain. Considering the significant size change between the inlet and minimum roll gap, a mixed Lagrangian-Eulerian mapping method, also known as the arbitrary Lagrangian-Eulerian (ALE) scheme, is applied to the computational domain. By using this coordinate mapping method, both the Eulerian and Lagrangain boundaries can be applied to the computational domain and significant distortion can be handled by re-meshing the entire domain during the simulation.

A specified uniform normal stress is applied at the inlet boundary, consistent with what is used in the Johanson model. Coulomb sliding friction, with a constant friction coefficient, is applied at the roll and inlet channel surfaces, again, consistent with the Johanson model. Unlike the FEM model of Cunningham [7] and Muliadi et al. [5], the computational domain in the current study has a longer release region, i.e., the region downstream of the minimum gap. Muliadi et al. [5] showed that the maximum roll normal stress in FEM simulations occurs at a location slightly upstream of the minimum gap, which is different from the Johanson model's assumption that the maximum roll normal stress occurs at the minimum gap. However, not only does this location vary depending on the material 
properties and boundary conditions, as found by Muliadi et al., but it has also been found in the current work to depend on the length of the release region. As shown in Table 1, as the release region length increases, the location of the maximum roll normal stress moves further downstream until it eventually occurs at the minimum gap location, consistent with Johanson's assumption. Therefore, in order to better simulate the roll compaction process, a longer release region is chosen in this study such that it does not affect the simulation results.

Within the domain, powder is modeled using CPE4R elements (reduced integration, plane strain elements). The powder stress-strain behavior is modeled using the Drucker-Prager/Cap (DPC) plasticity model. Details of the DPC model, including different experimental calibration procedures and values of the model parameters, can be found in works by Cunningham et al. [18], Han et al. [19], Michrafy et al. [20], Sinha et al. [21], and Krok et al. [22]. Note that this constitutive model assumes quasi-static behavior and does not include the effects of interstitial air. In the current study, density-independent DPC parameters are used in most of the simulations to compare with theoretical results since the Johanson model also assumes constant properties. Comparisons to density-dependent properties used within both two- and three-dimensional FEM simulations are also discussed in Section 5. The specific densityindependent DPC powder properties used in these studies are provided in Tables 2 and 3 and correspond to a particular brand of microcrystalline cellulose (Avicel PH-102, FMC-BioPolymer, PA, USA) as reported by Muliadi et al. [5], who, in turn, relied on the experimental data of Cunningham et al. [7]. The density-dependent DPC properties used in simulations for the same material were collected by Swaminathan et al. [23] and are given in Tables 4 and 5.

In order to compare to the maximum relative density predictions of the Johanson model, the material relative density at the minimum gap location is calculated in the FEM model using the total volumetric plastic strain as proposed by Gurson [24],

$$
\eta_{\theta=0}=\eta_{\text {initial }} \exp \left(-\left.\varepsilon_{v o l}^{p l}\right|_{\theta=0}\right)
$$

where $\eta_{\text {initial }}$ is the relative density at the inlet $(=0.311)$, which is also the relative density downstream of the feeder [6-8]. As is shown in Section 4, the inlet pressure used in the current work is smaller than the pressure corresponding to the tapped relative density. Thus, the powder at the inlet is in an uncompressed state. The quantity $\varepsilon_{\mathrm{vol}}{ }^{\mathrm{pl}}$ is the total volumetric plastic strain (PEQC4 value in Abaqus). 
As shown in Muliadi et al. [5], the FEM model element resolution is sufficiently fine to have negligible effect on the model results. The use of mass scaling, which is used by Abaqus/Explicit to improve computational efficiency [25], was also shown to have little influence on the current FEM results, especially the velocity fields. Results from these studies are summarized in Table 6.

\section{The Modified Johanson Model}

The Johanson model [2] divides flow through the roll compactor into two regions: a slip region located near the inlet where powder slips against the roll surfaces, and a no-slip region located downstream of the slip region where powder is assumed to have a streamwise speed equal to the roll periphery speed. Johanson's approach to modeling the stresses in the slip region and the nip angle remain unchanged in the model proposed here and, thus, are not rederived. Instead, the focus here is on the mechanics in the no-slip region.

In the no-slip region Johanson assumed that the powder velocity is one-dimensional. Hence, from conservation of mass, the mass contained within a small volume at the nip angle, $\alpha$, is the same mass at any other location, $\theta$, in the no-slip region (refer to Fig. 2),

$$
\eta_{\theta} V_{\theta}=\eta_{\alpha} V_{\alpha}
$$

where $\eta$ is the powder's relative density. The parameter $V$ is a small volume element given by,

$$
V_{\theta}=[S+D(1-\cos \theta)] \cos \theta \Delta L \mathrm{~W},
$$

where $S$ is the minimum gap width between the rolls, $D$ is the roll diameter, $\Delta L$ is a small displacement around the roll surface, and $W$ is the depth of the roll into the page (roll width).

In order to relate the powder's relative density to the applied pressure, a constitutive relation is required. Johanson assumed the following relation based on empirical observations,

$$
\frac{P_{\theta}}{P_{\alpha}}=\left(\frac{\eta_{\theta}}{\eta_{\alpha}}\right)^{K}
$$

where $P$ is the pressure and $K$ is a fitting constant. 
Combining Eqs. (2) - (4) gives the pressure in the no-slip region,

$$
P_{\theta}=P_{\alpha}\left[\frac{(1+S / D-\cos \alpha) \cos \alpha}{(1+S / D-\cos \theta) \cos \theta}\right]^{K},
$$

where the pressure at the nip angle $P_{\alpha}$ is found by integrating the pressure gradient in the slip region (refer to [2]).

Because the pressure is known at every angle, the roll force and torque may be calculated. The pressure in the noslip region is much larger than the pressure in the slip region so only the pressure contribution in the no-slip region is considered in the calculations. For example, the roll force, $F$, is,

$$
F \approx \int_{\theta=0}^{\theta=\alpha} \sigma_{\theta} W \frac{1}{2} D \cos \theta d \theta
$$

where,

$$
\sigma_{\theta}=P_{\theta}(1+\sin \delta)
$$

is the maximum principal stress on the roll's surface projected in the $y$ direction (Fig. 2) and $\delta$ is the powder's effective angle of internal friction. Equations (5) - (7) may be combined to give the roll force in terms of the maximum pressure $P_{0}$, which is located at the minimum gap location $(\theta=0)$,

$$
F \approx P_{0}(1+\sin \delta) W \frac{1}{2} D \int_{\theta=0}^{\theta=\alpha}\left[\frac{S / D}{(1+S / D-\cos \theta) \cos \theta}\right]^{K} \cos \theta d \theta
$$

A significant assumption in the Johanson model is that the flow is one-dimensional in the no-slip region. However, FEM simulations, such as the one shown in Fig. 3, indicate that the powder speed is faster at the roll surface than it is at the centerline. This observation has been reported previously $[5,7,15,16]$. Since the Johanson model assumes that the streamwise speed is equal to the streamwise projected roll speed at each cross-section, the model will overpredict the powder relative density.

Bi et al. [17] included a mass correction factor $f_{\theta}$ in the mass conservation equation (Eq. (2)) in order to account for the fact that the mass in each of the elements may vary due to multi-dimensional flow,

$$
\eta_{\theta} V_{\theta}=f_{\theta} \eta_{\alpha} V_{\alpha}
$$

Including this mass correction factor in the derivation, the resulting pressure in the no-slip region is, 


$$
P_{\theta}=P_{\alpha}\left[\frac{f_{\theta}(1+S / D-\cos \alpha) \cos \alpha}{(1+S / D-\cos \theta) \cos \theta}\right]^{K}
$$

Incorporating the mass correction factor into Eq. (8) gives,

$$
F \approx P_{0}(1+\sin \delta) W \frac{1}{2} D \int_{\theta=0}^{\theta=\alpha}\left(\frac{f_{\theta}}{f_{0}}\right)^{K}\left[\frac{S / D}{(1+S / D-\cos \theta) \cos \theta}\right]^{K} \cos \theta d \theta .
$$

Note that Eq. (11) is different than the one derived by Bi et al. [17]. The Bi et al. derivation (their Eq. (15)) had $f_{0}{ }^{K}$ as the pre-factor within the integral, which appears to be a derivation mistake,

$$
F_{\text {Bi et al. }} \approx P_{0}(1+\sin \delta) W \frac{1}{2} D \int_{\theta=0}^{\theta=\alpha}\left(f_{0}\right)^{K}\left[\frac{S / D}{(1+S / D-\cos \theta) \cos \theta}\right]^{K} \cos \theta d \theta .
$$

This mistake may be due to their early assumption that when $\alpha$ is small $(\alpha \approx 0), P_{\alpha}$ is approximated to be the maximum pressure $P_{0}$. In most cases, the nip angle is far from the minimum gap and $\alpha$ cannot be assumed zero. Hence, $P_{0}$ is much larger than $P_{\alpha}$. Besides this incorrect assumption, there also seem to be mistakes in the derivation of the force factor and maximum roll force pressure. Comparisons between predictions from Bi et al.'s model (Eq. Error! Reference source not found.) and the current modified model (Eq. (11)) are given in Section 5.

Equation (11) indicates that the angular dependence of the mass correction factor must be known in order to correctly predict the roll force. The FEM simulations were used with Eq. (9) to determine this functional form. The nip angle for this calculation was found directly from the unmodified Johanson model since prior work $[5,12]$ has shown that the Johanson model is reasonably accurate for this calculation. The mass correction factor normalized by the mass correction factor at the minimum gap width $(\theta=0)$ is plotted as a function of angular position normalized by the nip angle in Fig. 4 for a range of conditions (gap width-to-roll diameter, inlet stress, and powder-roll friction coefficient), which are identified in Table 7. Interestingly, these data vary little over a wide range of parameters. A curve of the form,

$$
\frac{f_{\theta}}{f_{0}}=1+\frac{1-f_{0}}{f_{0}}\left(\frac{\theta}{\alpha}\right)^{n}
$$

is proposed to fit the FEM data. Note that this fit has three parameters: the nip angle $\alpha$, the mass correction factor at the minimum gap $f_{0}$, and the exponent $n$. The nip angle is determined from the unmodified Johanson model, as 
described previously. As shown in Fig. 4 and Table 7, the exponent $n$ is independent of boundary conditions. Additional FEM simulations show that the exponent $n$ varies with the material properties. Bi et al.'s experiments provide similar observations [17]. For example, the current study uses Avicel PH-102 (FMC-BioPolymer, PA, USA), which gives a best fit to Eq. (12) when $n=1.25$. Additional FEM simulations using the DPC properties for lactose (Foremost Fast Flo 316) give $n=1.75$. Determination of the mass correction factor at the minimum gap width is described in the following paragraphs.

The mass correction factor fitting equation is substituted into Eq. (11) to give,

$$
\frac{F}{\frac{1}{2} D W P_{0}(1+\sin \delta)} \approx \int_{\theta=0}^{\theta=\alpha}\left[1+\frac{1-f_{0}}{f_{0}}\left(\frac{\theta}{\alpha}\right)^{n}\right]^{K}\left[\frac{S / D}{(1+S / D-\cos \theta) \cos \theta}\right]^{K} \cos \theta d \theta
$$

where the pressure at the minimum gap width $(\theta=0)$ is,

$$
P_{0}=P_{\alpha}\left[\frac{f_{0}(1+S / D-\cos \alpha) \cos \alpha}{S / D}\right]
$$

As stated previously, the nip angle $\alpha$ and pressure at the nip angle $P_{\alpha}$ are calculated using the unmodified Johanson model. In Table 8, which lists the FEM-computed and unmodified Johanson model values for $\alpha$ and $P_{\alpha}$, the unmodified Johanson model is shown to be reasonably accurate at providing nip angle while the pressure at nip angle derived is slightly larger than the simulation result. As discussed below, this difference can lead to a slightly larger prediction of ribbon relative density. Note that in Eq. (13) the mass correction factor at the minimum gap width, $f_{0}$, must be known. Commercial roll compactors typically operate with roll force or roll gap control. In either case, the force acting on the rolls is usually reported. Thus, Eqs. (14) and (15) may be used to solve for $f_{0}$.

Although in the current study the exponent $n$ for a certain material is derived directly from FEM simulation results, it is not necessary to run FEM simulations to determine this value. Recent work by Miguelez-Moran et al. [26] and Zhang et al. [27] have shown that there are many different techniques that can measure the ribbon bulk density distributions, such as sectioning, micro-indentation, and X-ray and terahertz pulse imaging. Once the ribbon density is measured in an experiment in which the roll force and roll gap are also known, then the fit parameters $\left(n, f_{0}\right)$ can be determined. For example, from the ribbon density, the maximum pressure can be calculated from the pressurerelative density relation (Eq. (4)), assuming the compressibility exponent is known from separate characterization 
experiments. The mass correction factor at the minimum gap width can then be found from Eq. (15) since the pressure at the nip angle (as well as the nip angle itself) may be calculated from the original Johanson analysis. Note that like the compressibility exponent, the effective internal friction angle is assumed known from characterization experiments. Lastly, the exponent $n$ in the mass correction expression can be found using Eq. (14) since the roll force is known.

The compressibility constant $K$ used in the Johanson model is normally found from punch and die experiments. In the current work, this $K$ is derived directly from the cap hardening parameters of DPC model (Table 3) where the relative density can be derived from the total volumetric plastic strain through Eq. (1). Figure 5 plots the pressure as a function of the relative density for Avicel PH-102 on a log-log axis. The data is fit well using,

$$
\frac{P}{P_{\text {initial }}}=\left(\frac{\eta}{\eta_{\text {initial }}}\right)^{K},
$$

where $\eta_{\text {initial }}=0.311$ is the inlet relative density (tapped relative density as mentioned previously) used in the FEM simulation and $P_{\text {initial }}=378.5 \mathrm{kPa}$ is the corresponding pressure according to the fit data. The compressibility (fitting) constant for this case is $K=5.08$. Compressibility constants between 4.5 and 5.9 were reported by Bi et al. [17] in their experiments using formulations consisting of several materials, including Avicel PH-102. Nesarikar et al. [28] also reported compressibility constants of between 4 and 6 in their formulations, which contained equal amounts of Avicel PH-102 and lactose as well as other components.

In addition to the pressure-density relation, the effective angle of internal friction $\delta$ used in the Johanson model is also determined from the DPC properties. The Mohr-Coulomb model used in Johanson's model assumes a linear relationship between shear and normal stresses at the shear yield surface while the Drucker-Prager Cap model used in the FEM simulations assumes a linear relationship between the deviatoric stress and pressure. Previous efforts $[25,29,30]$ attempted to develop relationships between the Mohr-Coulomb parameters and the DPC parameters using a variety of approaches, such as matching plane strain response, triaxial test response, or different strength criteria. Most of these relations are not suitable for large friction angles, including the one used by Muliadi et al. [5]. Thus, the current work modifies the relations originally developed by Pistrol et al. [29] since it can handle DPC friction 
angles up to $\beta=70^{\circ}$ (refer to the Appendix). The resulting relationship between the effective angle of internal friction $\delta$ used in the Mohr-Coulomb model and the angle of friction $\beta$ in the DPC model is,

$$
\sin \delta=\frac{3}{6+\tan \beta}\left(\frac{d}{P_{\text {initial }}}+\tan \beta\right) .
$$

\section{$5 \quad$ Results}

Figure 6 plots the relative density at the minimum gap width predicted using the two-dimensional FEM model, the original Johanson analysis, and the modified Johanson analysis described in Section 4. Here the FEM-computed relative densities are averaged across the thickness of the ribbon. Note that the relative density is almost constant across the ribbon at the minimum gap. A range of values for the powder-roll friction coefficient and roll geometry are shown. The remainder of the system parameters are given in the figure caption. All of the models predict similar trends, e.g., increasing ribbon relative density as powder-roll friction coefficient increases and dimensionless roll gap width decreases. Larger powder-roll friction coefficients produce larger shear stresses at the boundaries, which in turn increase the material plastic strain and the relative density (refer to Eq. (1)). Muliadi et al. [5] reported a similar trend. Smaller dimensionless gap widths also increase the amount of material plastic strain and relative density due to decreasing flow area.

Of particular note in Fig. 6 is that the original Johanson model gives much larger values than the modified model and FEM simulations. Moreover, in most cases the original Johanson predictions are unphysical, with ribbon relative densities greater than one. The modified Johanson model gives reasonable predictions that are approximately 5\% larger than the FEM results, with mass correction factors ranging from 0.5 to 0.9 . This slight over-prediction in relative density occurs because the pressure at the nip angle $P_{\alpha}$ in the modified Johanson model is derived directly from the unmodified model and is slightly larger than the FEM value. Clearly, accounting for multidimensional flow via a mass correction expression greatly improves the accuracy and usefulness of the Johanson model. Table 9 shows, for a particular case, comparisons between the FEM model, the original Johanson model, Bi et al.'s prediction, and the current modified Johanson model. Using Bi et al.’s (incorrect) derivation (Eq.

Error! Reference source not found.), the modified model gives an error of approximately $24 \%$. 
Additional FEM simulations were developed in order to determine how density-dependent DPC properties and three-dimensional flow change the accuracy of the modified Johanson model. First, a three-dimensional, densityindependent FEM model with frictionless cheekplates was compared to the two-dimensional results. For the three dimensional simulations, the maximum pressure and relative density are averaged over both the width and thickness of the ribbon. As summarized in Table 10, the two-dimensional model gives accurate predictions as compared to the three-dimensional model, with relative differences of less than $1 \%$. The three-dimensional FEM simulations, however, require far more computational resources, with wall clock times approximately 10 times larger than those for the two-dimensional simulations.

Next, several three-dimensional, density-dependent FEM simulations were performed in which the powdercheekplate friction coefficient was varied with values between 0 and 0.55 . The compressibility constant and effective angle of internal friction used in the modified and original Johanson models were found using the procedures described in Section 4, but using the density-dependent DPC properties (Tables 4 and 5). Note here the effective angle of internal friction was derived from the average friction angle in the DPC model over the range of all relative densities using Eq. (17). Figure 7 shows that the proposed mass correction factor relation (Eq. (13)) is still a good fitting equation; however, for the same material, the exponent $n$ increases with increasing powdercheekplate friction coefficient. For a sufficiently small friction coefficient $(\leq 0.3)$, the exponent $n$ derived from twodimensional simulations is still a good mass correction factor value, giving errors of less than $10 \%$ from the value fit from the three-dimensional simulations.

Lastly, the published experimental results of Cunningham [7] were compared to predictions from two-dimensional, density-dependent FEM simulations and the modified Johanson model, as shown in Table 11. The material used in both the experiments and simulations was Avicel PH-102 (DPC data in Tables 4 and 5). Note that in the FEM simulation, the powder-roll friction coefficient, which is a prescribed value in the modified Johanson model, is fitted to give the same roll force value as the experiment results since this coefficient was not reported in Cunningham's work. An important point is that the Cunningham ribbon relative density measurement is for the ribbon downstream of the minimum gap width, which means that the relative density includes the effects of elastic springback. Avicel- 
PH102, the material used here, deforms primarily in a plastic manner and exhibits little elastic rebound according to LaMarche et al. [31]; however, it is not zero. The FEM simulations show a small relative density change, less than $3 \%$, between the minimum gap and post-roll compaction relative densities. The post-roll compaction relative density predicted by the FEM model is within $1 \%$ of the experimental measurement, indicating an excellent prediction. The modified Johanson model prediction, which provides only a minimum gap relative density prediction, is approximately $2 \%$ larger than the corresponding FEM model prediction and less than 5\% larger than the post-roll compaction experimental result. Thus, we conclude that the modified Johanson model gives accurate results. If materials that have a larger elastic response, such as lactose, are roll compacted, then the modified Johanson model prediction of the minimum gap width relative density could be potentially much larger than the actual post-roll compaction value.

\section{Conclusions}

Prior work [4] has shown that Johanson's roll compaction model over-predicts, and in some cases, provides unphysical values for a ribbon's relative density. This inaccuracy has been shown to be due to the one-dimensional flow assumption in the model. Bi et al. [16] proposed the use of a mass correction factor to account for multidimensional flow effects; however, the expression reported in their publication has derivation errors. In the present work, a mass correction approach is also used, but unlike Bi et al's work, the dependence of the mass correction factor on position within the roll compactor is accounted for. The resulting prediction of minimum gap ribbon relative density is shown to be only a few percent larger than FEM-predicted relative densities. Like the original Johanson model, predictions from this modified model can be quickly calculated and, thus, is well suited for control system and preliminary design calculations.

The empirical mass correction factor relation proposed here (Eq. (13)) has two fitting parameters: a power constant $n$ and the mass correction factor at the minimum gap width $f_{0}$. Using measurements of the roll force and minimum gap width, which are often reported in commercial roll compaction equipment, these fitting parameters can be determined. The value for $n$ is shown to be independent of powder-roll friction coefficient and dimensionless gap 
width, but does depend on the compaction properties of the material and the powder-cheekplate friction coefficient. Once the value of $n$ is determined, the parameter $f_{0}$ is then just a function of the roll force.

Several improvements to this modified model should be considered in future studies. For example, can the fitting parameters $n$ and $f_{0}$ be determined a priori from independent models or experiments? In addition, what modifications to the model should be made to incorporate springback of the ribbon downstream of the minimum gap width? Even without these additions, the current model is much more accurate the original Johanson model.

\section{Acknowledgements}

The authors are grateful to the National Science Foundation Engineering Research Center for Structured Organic Particulate Systems (NSF ERC-SOPS, 0951845-EEC) for financial support. We also greatly appreciate the Abaqus guidance and density-dependent DPC data (Tables 4 and 5) collected by Shrikant Swaminathan at Purdue University.

\section{References}

[1] S.G. von Eggelkraut-Gottanka, S.A. Abed, W. Muller, P.C. Schmidt, Roller compaction and tableting of St. John's wort plant dry extract using a gap width and force controlled roller compactor. II. Study of roller compaction variables on granule and tablet properties by a $3 \times 3$ factorial design, Pharmaceutical Development and Technology 7 (2002) 447-455.

[2] J.R. Johanson, A rolling theory for granular solids, ASME Journal of Applied Mechanics E32 (1965) 842-848.

[3] V.P. Katashinskii, Analytical determination of specific pressure during the rolling of metal powders, Soviet Powder Metallurgy and Metal Ceramics 10 (1986) 765-772.

[4] G.Y. Gun, S.A. Stebunov, V.P. Katashinskii, Computer modeling and investigation of the metal powder rolling processes, Powder Metallurgy and Metal Ceramics 25 (1986) 8-11. 
[5] A.R. Muliadi, J.D. Litster, C.R. Wassgren, Modeling the powder roll compaction process: comparison of 2-D finite element method and the rolling theory for granular solids (Johanson's model), Powder Technology 221 (2012) 90-100.

[6] A.R. Muliadi, J.D. Litster, C.R. Wassgren, Validation of 3-D finite element analysis for predicting the density distribution of roll compacted pharmaceutical powder, Powder Technology 237 (2013) 386-399.

[7] J.C. Cunningham, Experimental studies and modeling of the roller compaction of pharmaceutical powders: PhD Thesis, Drexel University; 2005.

[8] A. Mazor, L.P. Gabdarillas, A.D. Ryck, A. Michrafy, Effect of roll compactor sealing system designs: A finite element analysis, Powder Technology 289 (2016) 21-30.

[9] T.J. Patterson, Prediction of the stress at the inlet of the nip region in a roll compactor: M.S. Thesis, Purdue University; 2014.

[10] A.W. Jenike, R.T. Shield, On the plastic flow of Coulomb solids beyond original failure, JAM 27 (1959) 599602.

[11] Z. H. Gu, P. C. Arnold, A. G. McLean, Consolidation-related bulk density and permeability models for bulk solids, Powder Technology 72 (1992) 39-44.

[12] G. Bindhumadhavan, J.P.K. Seville, M.J. Adams, R.W. Greenwood, S. Fitzpatrick, Roll compaction of a pharmaceutical excipient: experimental validation of rolling theory for granular solids, Chemical Engineering Science 60 (2005) 3891-3897.

[13] A. Krok, M. Peciar, R. Fekete, Using the DPIV optical technique to measure the velocity of powder material in the space between the rollers in a roll compactor, Powder Technology 262 (2014) 131-141.

[14] Y.A. Yusof, A.C. Smith, B.J. Briscoe, Roll compaction of maize powder, Chemical Engineering Science 60 (2005) 3919-3931.

[15] A. Zavaliangos, R.T. Dec, R.K. Komarek, Analysis of powder processing in the roller press using finite element modeling, in: XXII International Mineral Processing Congress, Cape Town, South Africa, 2003.

[16] E. Orowan, The Calculation of Roll Pressure in Hot and Cold Flat Rolling, Research on the Rolling of Strip, 1960, pp. 10.

[17] M. Bi, F. Alvarez-Nunez, F. Alvarez, Evaluating and modifying Johanson's rolling model to improve its predictability, J Pharm Sci. 103 (2014) 2062-2071. 
[18] J.C. Cunningham, I.C. Sinka, A. Zavaliangos, Analysis of tablet compaction. I. Characterization of mechanical behavior of powder and powder/tooling friction, Journal of Pharmaceutical Sciences 93 (2004) 2022-39.

[19] L.H. Han, J.A. Elliott, A.C. Bentham, A. Mills, G.E. Amidon, B.C. Hancock, A modified Drucker-Prager Cap model for die compaction simulation of pharmaceutical powders, International Journal of Solids and Structures 45 (2008) 3088-3106.

[20] A. Michrafy, H. Diarra, J.A. Dodds, M. Michrafy, Experimental and numerical analyses of homogeneity over strip width in roll compaction, Powder Technology 206 (2011) 154-160.

[21] T. Sinha, J.S. Curtis, B.C. Hancock, C.Wassgren, A study on the sensitivity of Drucker-Prager cap model parameters during the decompression phase of powder compaction simulations, Powder Technology 198 (2010) $315-324$.

[22] A. Krok, M. Peciar, R. Fekete, Numerical investigation into the influence of the punch shape on the mechanical behavior of pharmaceutical powders during compaction, Particuology 16 (2014) 116-131.

[23] S. Swaminathan, J. Hilden, B. Ramey, C. Wassgren, Modeling the formation of debossed features on a pharmaceutical tablet, Journal of Pharmaceutical Innovation (2016) Unpublished.

[24] A.L. Gurson, Continuum theory of ductile rupture by void nucleation and growth: Part 1-yield criteria and flow rules for porous ductile media, ASME Journal of Engineering Materials and Technology 99 (1977) 2-15.

[25] Abaqus Analysis User's Manual, Hibbitt, Karlsson and Sorensen, Inc., Rhode Island, 2001.

[26] A.M. Miguelez-Moran, C.Y. Wu, H. Dong, J. P.K. Seville, Characterisation of density distributions in rollercompacted ribbons using micro-indentation and X-ray micro-computed tomography, European Journal of Pharmaceutics and Biopharmaceutics 72 (2009) 173-182.

[27] J. Zhang, C. Pei, S. Schiano, D. Heaps, C.Y. Wu, The application of terahertz pulsed imaging in characterising density distribution of roll-compacted ribbons, European Journal of Pharmaceutics and Biopharmaceutics (2016)

[28] V. Nesarikar, N. Vatsaraj, C. Patel, W. Early, P. Pandey, O. Sprockel, Z. Gao, R. Jerzewski, R. Miller, M. Levin, Instrumented roll technology for the design space development of roller compaction process, Int. J. Pharm. 426 (2012) 116-131.

[29] J. Pistrol, F. J. Falkner, D. Adam, C. Adam, Comparison of constitutive soil models for the simulation of dynamic roller compaction, European Congress on Computational Methods in Applied Sciences and Engineering, J. Eberhardsteiner et al. (eds.), Vienna, Austria (2012). 
[30] H. Jiang, Y. Xie, A note on the Mohr-Coulomb and Drucker-Prager strength criteria, Mechanics Research Communications 38 (2011) 309-314.

[31] K. LaMarche, D. Buckley, R. Hartley, F. Qian, S Badawy, Assessing materials' tablet compaction properties using the Drucker-Prager Cap model, Powder Technology 267 (2014) 208-220.

\section{Appendix}

For convenience, details of Pistrol et al.'s work [23] relating Mohr-Coulomb and Drucker-Prager Cap parameters are presented here. Two specific states of stress were chosen to match one edge of the Mohr-Coulomb yield pyramid with the Drucker-Prager shear yield cone. The stress at the apex of both models is,

$$
\sigma_{a}=\frac{c}{\tan \phi}
$$

where $c$ is the cohesion and $\phi$ is the angle of internal friction in the Mohr-Coulomb model. For the case where the Drucker-Prager cone is tangential to the Mohr-Coulomb pyramid at its compression meridian, the yield stress in uniaxial compression can be written as,

$$
\sigma_{c}=\frac{2 c}{\sec \phi-\tan \phi}
$$

The angle of friction $\beta$ and the cohesion $d$ of the Drucker-Prager model then can be expressed as,

$$
\begin{aligned}
& \tan \beta=\frac{3 \sigma_{c}}{3 \sigma_{a}+\sigma_{c}}=\frac{6 \sin \phi}{3-\sin \phi}, \\
& d=\frac{3 \sigma_{c}}{3 \sigma_{a}+\sigma_{c}} \sigma_{a}=\frac{\tan \beta}{\tan \phi} c .
\end{aligned}
$$

In the current work, the Mohr-Coulomb parameters expressed in terms of the (FEM) DPC parameters are desired. Hence, Eqs. (20) and (21) are re-arranged to give,

$$
\begin{aligned}
& \sin \phi=\frac{3 \tan \beta}{6+\tan \beta}, \\
& c=\frac{\tan \phi}{\tan \beta} d .
\end{aligned}
$$


Note that it is the effective angle of internal friction $\delta$ in the Mohr-Coulomb model is used in Johanson's model, not the internal friction angle $\phi$. The effective internal friction angle $\delta$ may be found from the inlet pressure $P_{\text {initial }}$ since the corresponding effective yield locus is the upper limit of all stress conditions, as shown in Fig. A.1. From the geometry in Fig. A.1, the effective angle of internal friction $\delta$ is,

$$
\sin \delta=\left(\frac{c}{P_{\text {initial }} \tan \phi}+1\right) \sin \phi
$$

Substituting Eqs. (22) and (23) into Eq. (24), the final relation between $\delta$ and $\beta$ becomes,

$$
\sin \delta=\frac{3}{6+\tan \beta}\left(\frac{d}{P_{\text {initial }}}+\tan \beta\right)
$$




\section{List of Figures}

Fig. 1. A schematic of the geometry modeled in the FEM simulations.

Fig. 2. A schematic showing powder volume elements in the no-slip region.

Fig. 3. Streamwise component of the powder velocity generated from an FEM simulation. The inlet stress, minimum gap width, roll diameter, and powder-roll friction coefficient are, respectively, $100 \mathrm{kPa}, 4 \mathrm{~mm}, 200 \mathrm{~mm}$, and 0.5 . The remainder of the material properties are given in Tables 2 and 3.

Fig. 4. The mass correction factor normalized by the mass correction factor at $\theta=0$ plotted as a function of angular position normalized by the nip angle as measured from FEM simulations (Table 7). The curve fit proposed in Eq. (13) is shown as a dashed line.

Fig. 5. Pressure-density relation of Avicel PH-102 derived from cap hardening parameters (Table 3).

Fig. 6. Maximum relative densities as functions of (a) powder-roll friction coefficient and (b) dimensionless roll geometry $S / D$. The inlet stress, minimum gap width, roll diameter, and powder-roll friction coefficient are, respectively, (a) $200 \mathrm{kPa}, 4 \mathrm{~mm}, 200 \mathrm{~mm}$, and N/A, and (b) $200 \mathrm{kPa}, \mathrm{N} / \mathrm{A}, 200 \mathrm{~mm}$, and 0.35 . The remainder of the material properties are given in Tables 2 and 3.

Fig. 7. The mass correction factor normalized by the mass correction factor at $\theta=0$ plotted as a function of angular position normalized by the nip angle as measured from FEM simulations for powder-cheekplate friction coefficient of (a) 0.15 and (b) 0.35 . The curve fits proposed in Eq. (13) for different exponent $n$ are shown as dashed lines. The inlet stress, minimum gap width, roll diameter, roll width, and powder-roll friction coefficient are $200 \mathrm{kPa}, 2 \mathrm{~mm}$, $100 \mathrm{~mm}, 20 \mathrm{~mm}$, and 0.35 , respectively. The remainder of the material properties are given in Tables 4 and 5 .

Fig. A.1. The effective yield locus and internal yield locus in the $\sigma-\tau$ plane. 


\section{List of Tables}

Table 1. The angle of the maximum roll normal stress as measured from the minimum gap location as a function of the length of the release region (refer to Fig. 1). The inlet stress, gap width, roll diameter, and powder-roll friction coefficient for the simulations are, respectively, $100 \mathrm{kPa}, 3 \mathrm{~mm}, 200 \mathrm{~mm}$, and 0.5 . The remainder of the material properties are given in Tables 2 and 3 .

Table 2. Density-independent cap plasticity and elastic parameters for the simulated powder.

Table 3. Density-independent cap hardening parameters for the simulated powder.

Table 4. Density-dependent cap plasticity and elastic parameters for the simulated powder.

Table 5. Density-dependent cap hardening parameters for the simulated powder.

Table 6. Mass scaling study results. The inlet stress, minimum gap width, roll diameter, and powder-roll friction coefficient are, respectively, $100 \mathrm{kPa}, 4 \mathrm{~mm}, 200 \mathrm{~mm}$, and 0.55 . The remainder of the material properties are given in Tables 2 and 3.

Table 7. The boundary conditions for the different FEM simulations shown in Fig. 4. The material properties are given in Tables 2 and 3.

Table 8. Comparison of predictions of the nip angle and pressure at the nip angle between the FEM model and Johanson's model. The inlet stress, minimum gap width, roll diameter, and powder-roll friction coefficient are, respectively, $200 \mathrm{kPa}, 4 \mathrm{~mm}, 200 \mathrm{~mm}$, and 0.50 . The remainder of the material properties are given in Tables 2 and 3.

Table 9. Comparison between predictions of FEM model, original Johanson model, Bi et al.'s derivation and current modified Johanson model. The inlet stress, minimum gap width, roll diameter, powder-roll friction coefficient and 
roll force (derived from FEM simulation results and served as an input value to Bi et al.'s model and current modified Johanson model) are, respectively, $200 \mathrm{kPa}, 4 \mathrm{~mm}, 200 \mathrm{~mm}, 0.35$ and $1817.2 \mathrm{kN}$. The remainder of the material properties are given in Tables 2 and 3.

Table 10. Comparison between the three-dimensional FEM model and two-dimensional FEM model. The inlet stress, minimum gap width, roll diameter, and powder-roll friction coefficient are, respectively, $200 \mathrm{kPa}, 4 \mathrm{~mm}, 200 \mathrm{~mm}$, and 0.35 . The remainder of the material properties are given in Tables 2 and 3.

Table 11. Comparison of the relative density predictions between Cunningham's experiment [6], the twodimensional FEM model (with density-dependent DPC properties, refer to Tables 4 and 5), and the modified Johanson model. 


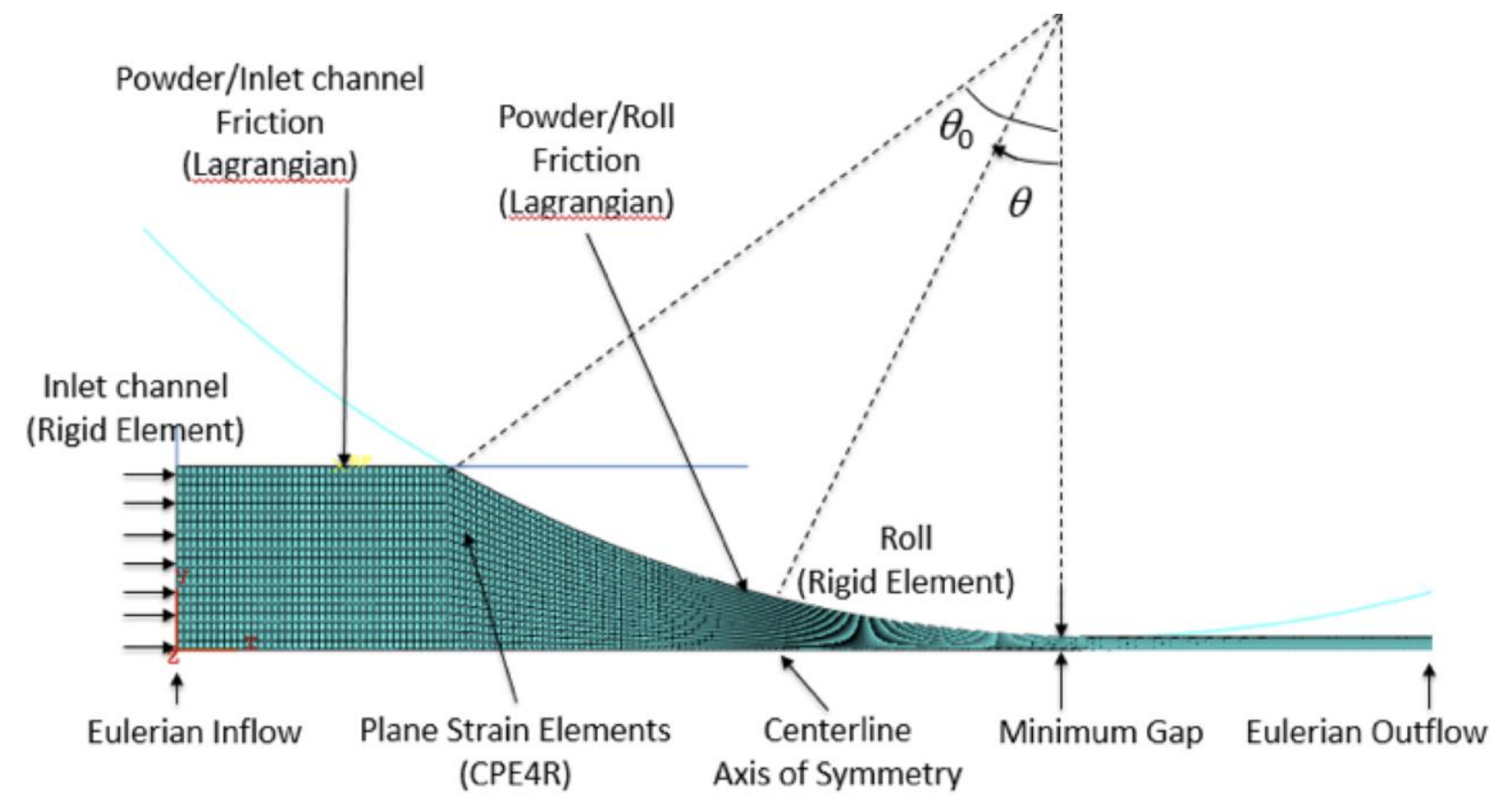




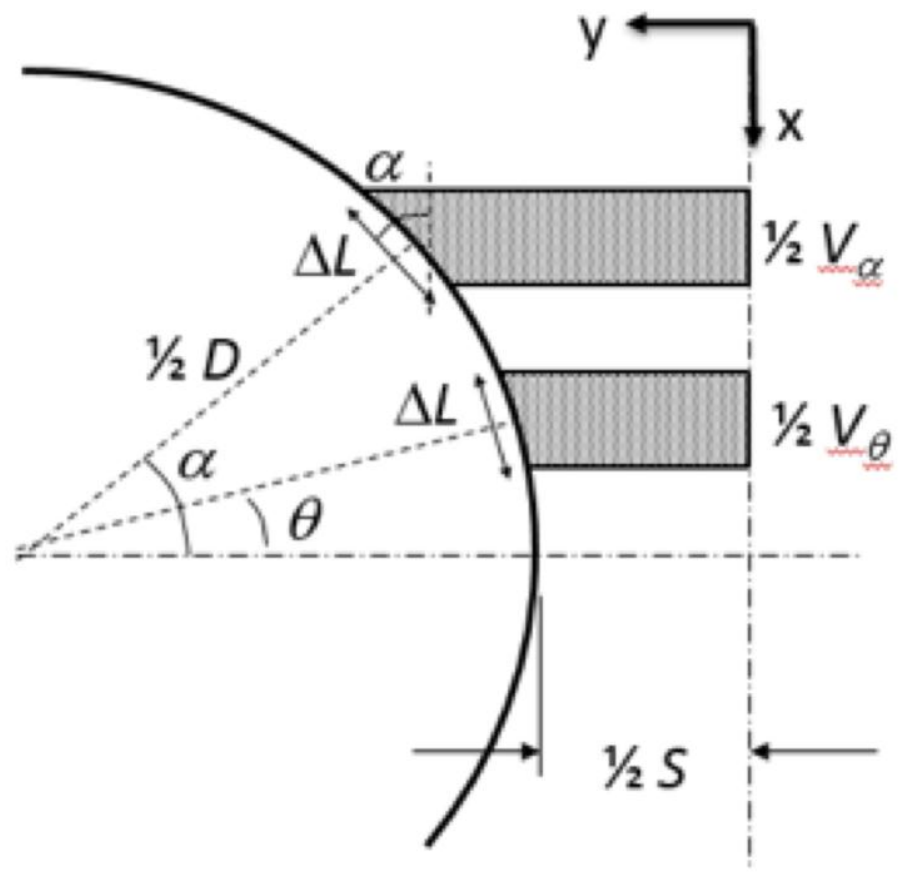




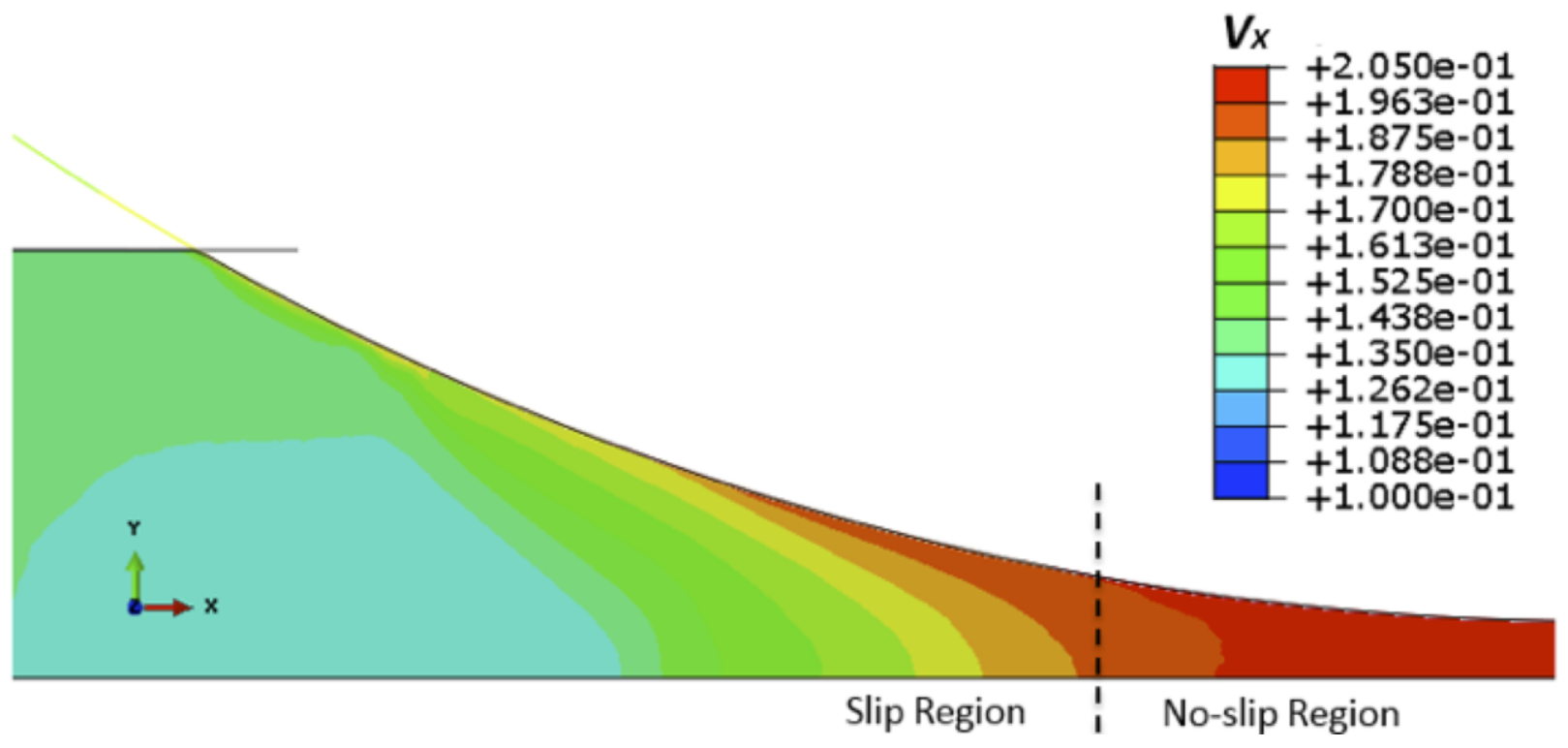




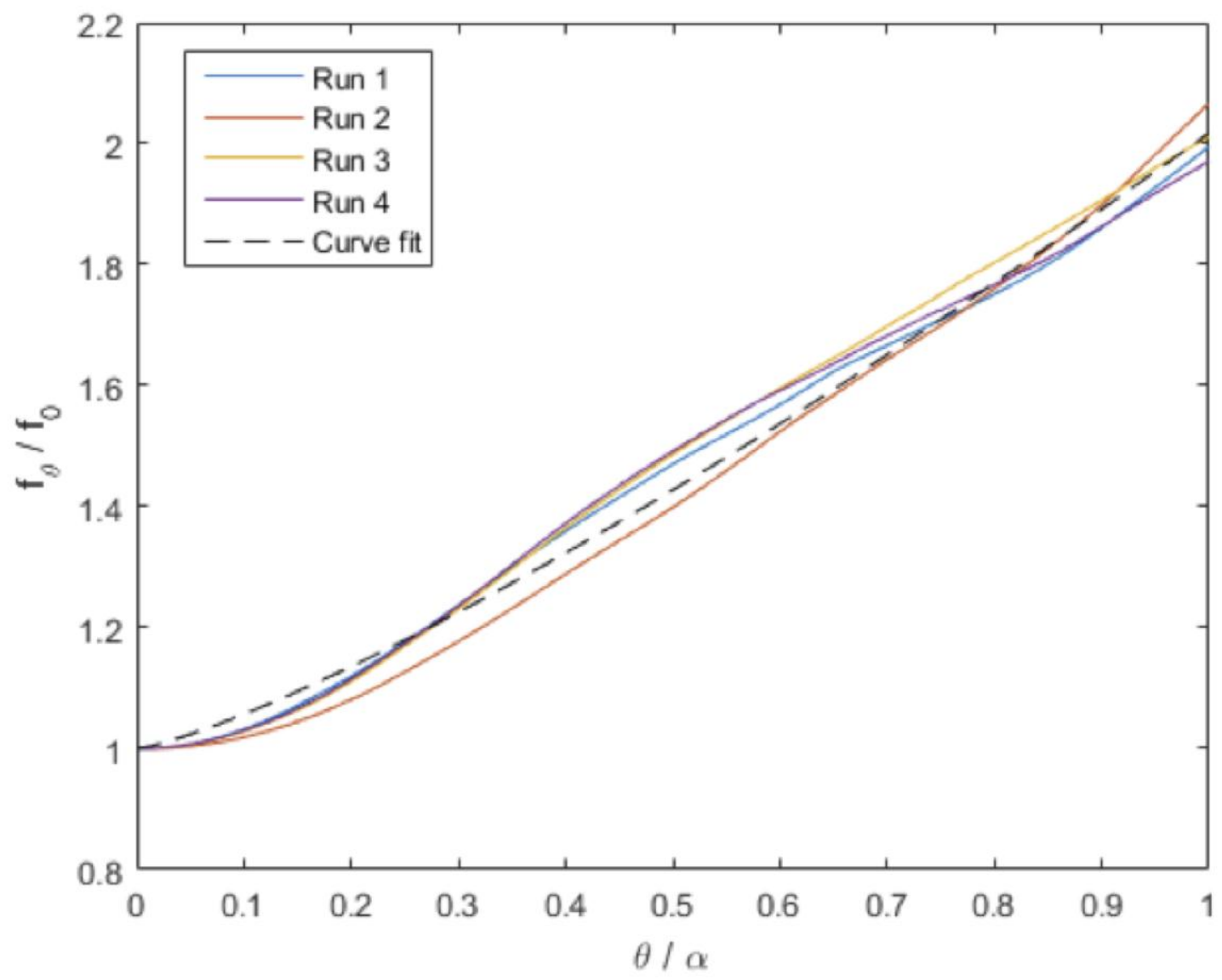




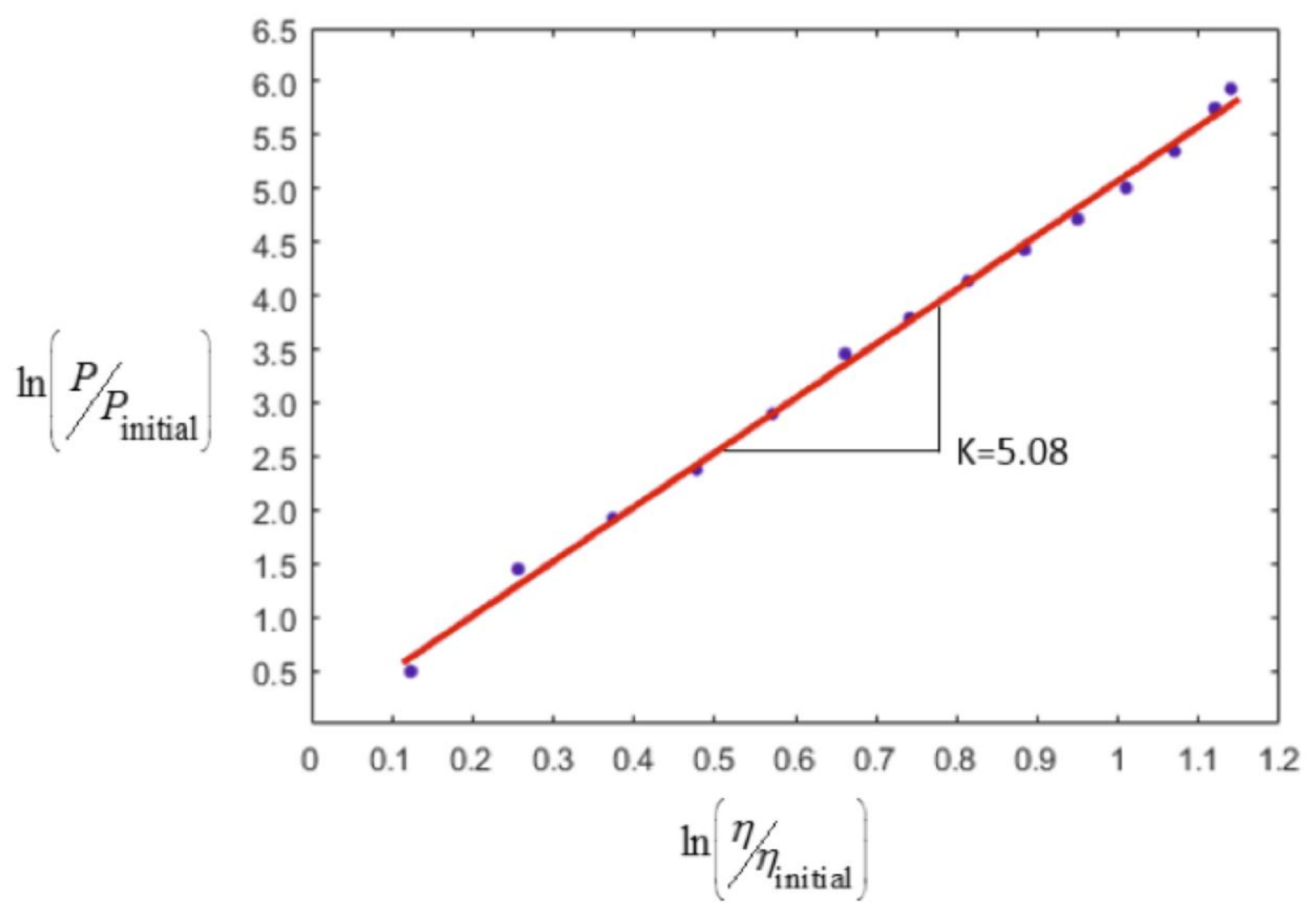




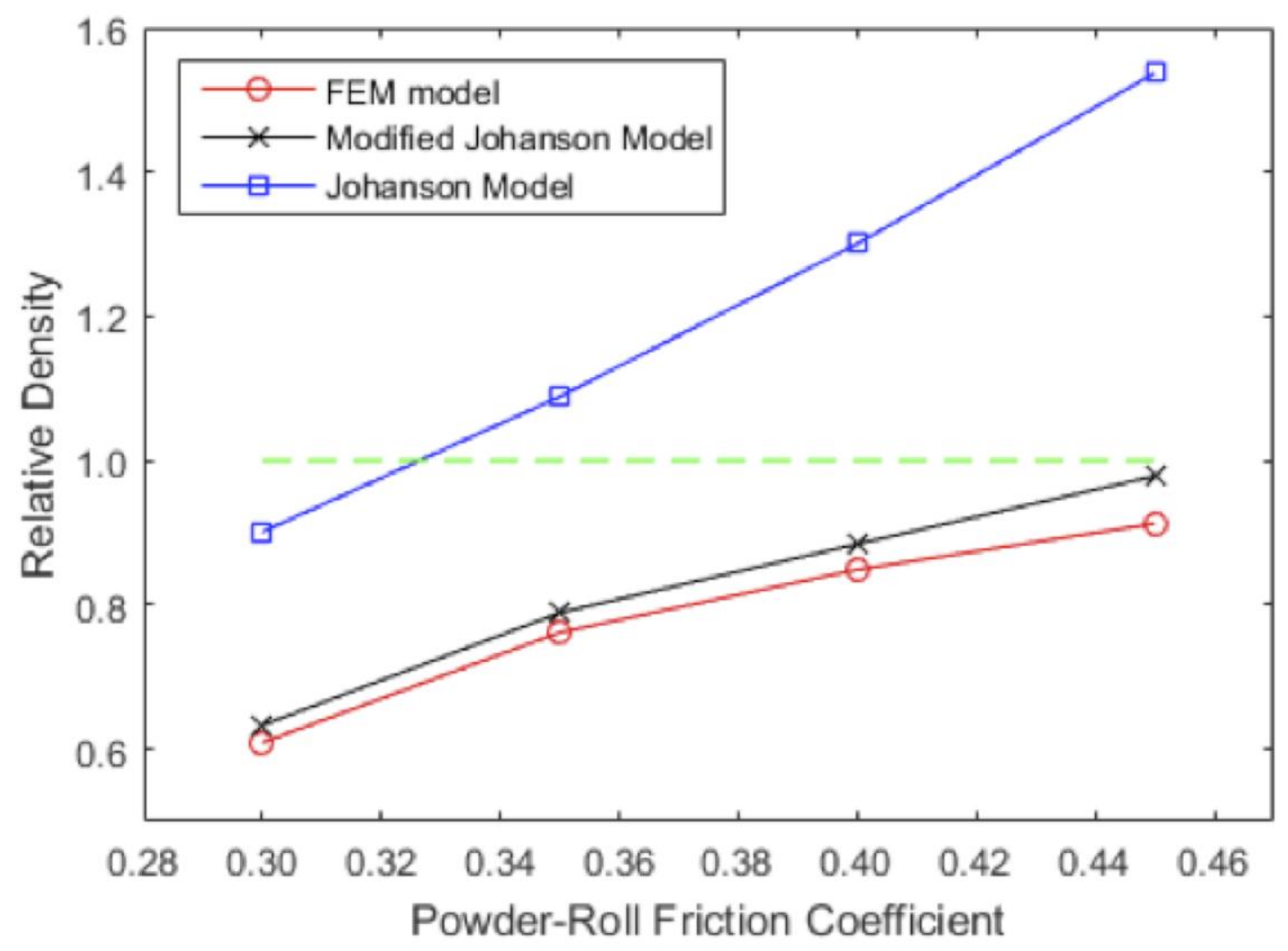




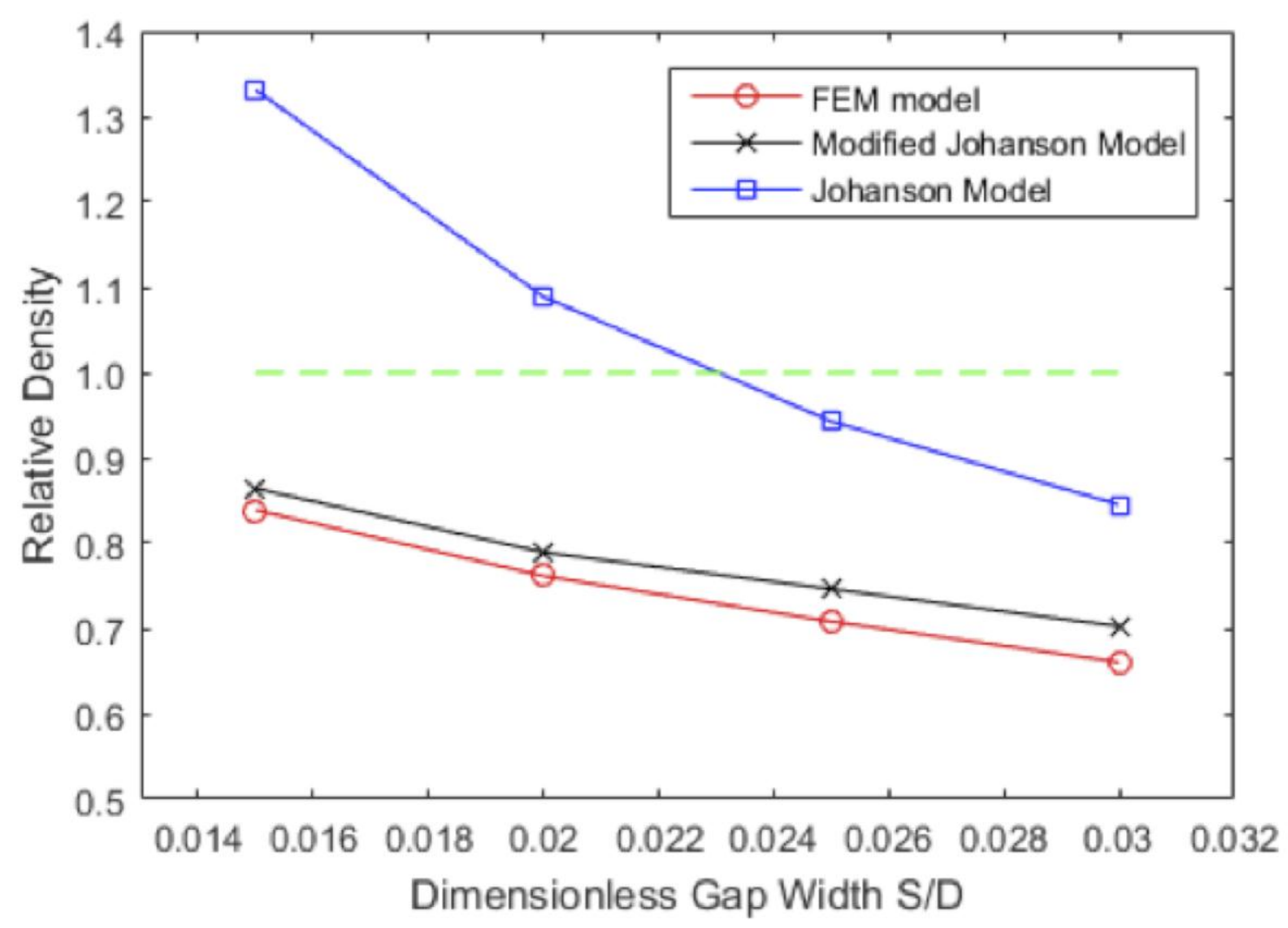




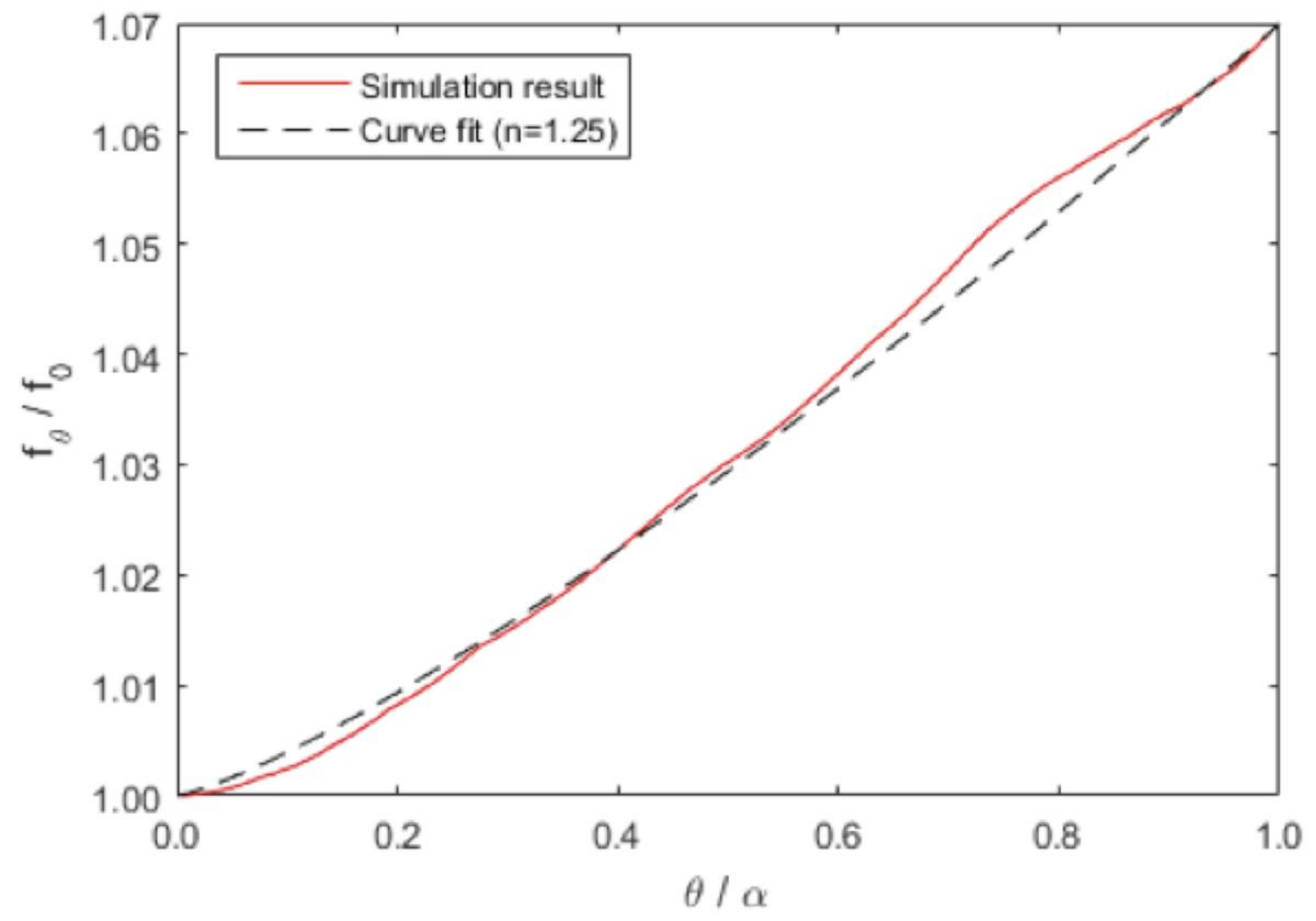




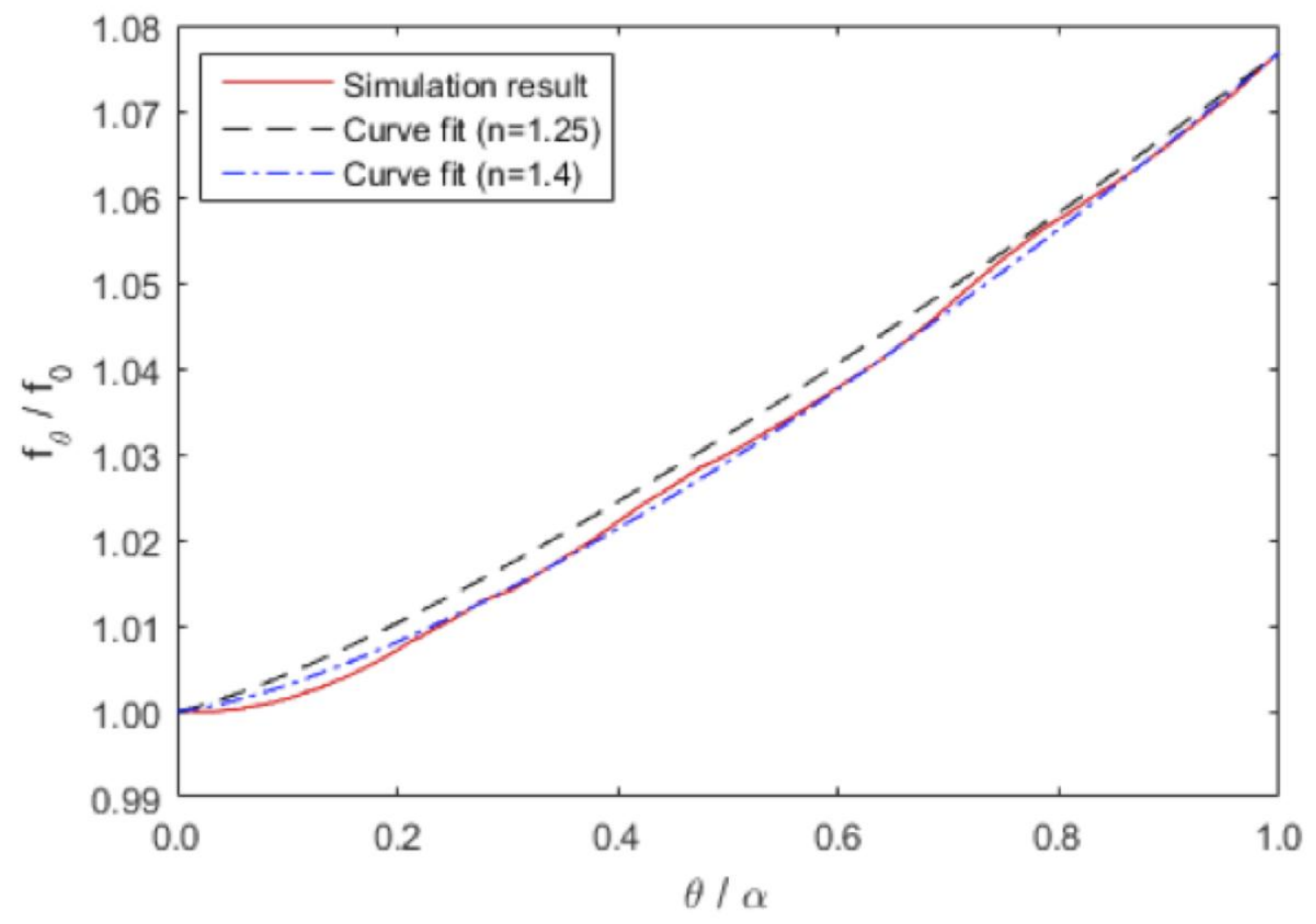




\begin{tabular}{lllll}
\hline $\begin{array}{l}\text { Length of the release } \\
\text { region, } l_{3}(\mathrm{~mm})\end{array}$ & 0 & 5 & 10 & 15 \\
\hline $\begin{array}{l}\text { Angle at which the } \\
\text { maximum roll normal stress } \\
\text { occurs, } \theta \text { (degree) }\end{array}$ & 1.72 & 0.86 & 0.29 & 0 \\
\hline
\end{tabular}




\begin{tabular}{lllll}
\hline Cohesion (MPa) & $\begin{array}{l}\text { Friction angle } \\
\text { (degree) }\end{array}$ & Cap eccentricity & $\begin{array}{l}\text { Young's modulus } \\
\text { (MPa) }\end{array}$ & Poisson's ratio \\
\hline 0.127 & 56.5 & 0.166 & 481 & 0.062 \\
\hline
\end{tabular}




\begin{tabular}{lllllllll}
\hline Volumetric plastic strain & 0.000 & 0.257 & 0.478 & 0.662 & 0.814 & 0.950 & 1.070 & 1.140 \\
\hline Hydrostatic yield stress (MPa) & 0.04 & 1.61 & 4.08 & 12.00 & 23.07 & 42.30 & 79.60 & 143.0 \\
\hline
\end{tabular}




\begin{tabular}{llllll}
\hline Relative density & $\begin{array}{l}\text { Cohesion } \\
(\mathrm{MPa})\end{array}$ & $\begin{array}{l}\text { Friction angle } \\
\text { (degree) }\end{array}$ & $\begin{array}{l}\text { Cap } \\
\text { eccentricity }\end{array}$ & $\begin{array}{l}\text { Young's } \\
\text { modulus (MPa) }\end{array}$ & Poisson's ratio \\
\hline 0.411 & 0.29 & 68.87 & 0.320 & 519 & 0.100 \\
0.492 & 1.15 & 67.37 & 0.331 & 689 & 0.106 \\
0.589 & 4.28 & 67.95 & 0.357 & 982 & 0.115 \\
0.686 & 6.15 & 64.93 & 0.381 & 1140 & 0.129 \\
0.783 & 11.80 & 66.60 & 0.465 & 2770 & 0.144 \\
0.881 & 15.80 & 65.82 & 0.599 & 5610 & 0.170 \\
\hline
\end{tabular}




\begin{tabular}{lcccccc}
\hline Volumetric plastic strain & 0.280 & 0.458 & 0.639 & 0.791 & 0.923 & 1.041 \\
\hline Hydrostatic yield stress (MPa) & 5.31 & 7.72 & 13.70 & 23.70 & 41.40 & 78.00 \\
\hline
\end{tabular}




\begin{tabular}{lllll}
\hline Mass scaling factor & $\begin{array}{l}\text { Kinetic energy KE } \\
(\mathrm{J})\end{array}$ & $\begin{array}{l}\text { Internal energy } \\
\mathrm{IE}(\mathrm{J})\end{array}$ & KE/IE & $\begin{array}{l}\text { Convergence wall clock } \\
\text { time }(\mathrm{min})\end{array}$ \\
\hline 0 & 0.0564 & 30335 & $1.86 \mathrm{E}-06$ & 228 \\
50 & 2.8645 & 28690 & $9.98 \mathrm{E}-05$ & 53 \\
500 & 28.4579 & 27590 & $1.03 \mathrm{E}-03$ & 30 \\
\hline
\end{tabular}




\begin{tabular}{lllll}
\hline Run \# & Inlet stress $\sigma_{\text {inlet }}(\mathrm{kPa})$ & Minimum gap width $(\mathrm{mm})$ & Roll diameter $(\mathrm{mm})$ & Powder-roll friction coefficient \\
\hline 1 & 200 & 4 & 200 & 0.35 \\
2 & 100 & 4 & 200 & 0.5 \\
3 & 200 & 4 & 200 & 0.5 \\
4 & 100 & 2 & 200 & 0.5 \\
\hline
\end{tabular}




\begin{tabular}{lll}
\hline & Nip angle $\alpha$ (degree) & Pressure at the nip angle $P_{\alpha}(\mathrm{MPa})$ \\
\hline FEM model & 18.54 & 4.10 \\
Johanson model & 18.33 & 5.91 \\
\hline
\end{tabular}




\begin{tabular}{lllllll}
\hline & $\begin{array}{l}\text { Mass } \\
\text { correction } \\
\text { factor } f_{0}\end{array}$ & Error & $\begin{array}{l}\text { Maximum } \\
\text { pressure } P_{0}(\mathrm{~Pa})\end{array}$ & Error $^{+}$ & $\begin{array}{l}\text { Relative density at } \\
\text { the minimum gap } \\
\eta_{0}\end{array}$ & Error $^{+}$ \\
\hline FEM model & 0.771 & N/A & $3.49 \mathrm{E}+07$ & N/A & 0.762 & N/A \\
$\begin{array}{l}\text { Original } \\
\text { Johanson model }\end{array}$ & N/A & N/A & $2.18 \mathrm{E}+08$ & $524 \%$ & 1.089 & $43 \%$ \\
$\begin{array}{l}\text { Bi et al.'s } \\
\text { derivations }\end{array}$ & 0.8984 & $16 \%$ & $1.0565 \mathrm{e}+08$ & $203 \%$ & 0.9437 & $24 \%$ \\
$\begin{array}{l}\text { Current Modified } \\
\text { Johanson model }\end{array}$ & 0.751 & $-2.59 \%$ & $4.26 \mathrm{E}+07$ & $22 \%$ & 0.789 & $3.57 \%$ \\
\hline $\begin{array}{l}{ }^{+} \text {As compared to the FEM model. } \\
\text { A }\end{array}$ & & & & &
\end{tabular}




\begin{tabular}{lllll}
\hline & $\begin{array}{l}\text { Maximum pressure } \\
P_{0}(\mathrm{~Pa})\end{array}$ & Error & $\begin{array}{l}\text { Relative density at } \\
\text { the minimum gap } \eta_{0}\end{array}$ & Error \\
\hline 3D FEM model & $3.20 \mathrm{E}+07$ & $\mathrm{~N} / \mathrm{A}$ & 0.751 & $\mathrm{~N} / \mathrm{A}$ \\
& & & & $-0.53 \%$ \\
\hline 2D FEM model & $3.18 \mathrm{E}+07$ & $-0.63 \%$ & 0.747 & \\
\hline
\end{tabular}




\begin{tabular}{lllll}
\hline & Roll Gap $(\mathrm{mm})$ & $\begin{array}{l}\text { Roll Force } \\
(\mathrm{N} / \mathrm{mm})\end{array}$ & $\begin{array}{l}\text { Relative density } \\
\text { at the minimum } \\
\text { gap } \eta_{0}\end{array}$ & $\begin{array}{l}\text { Ribbon Relative } \\
\text { Density } \eta_{\text {ribbon }}\end{array}$ \\
\hline Experiment & 1.89 & 242.9 & N/A & 0.636 \\
FEM model & 2 & 227.1 & 0.6522 & 0.6335 \\
Modified Johanson model & 2 & 227.1 & 0.6655 & N/A \\
\hline
\end{tabular}




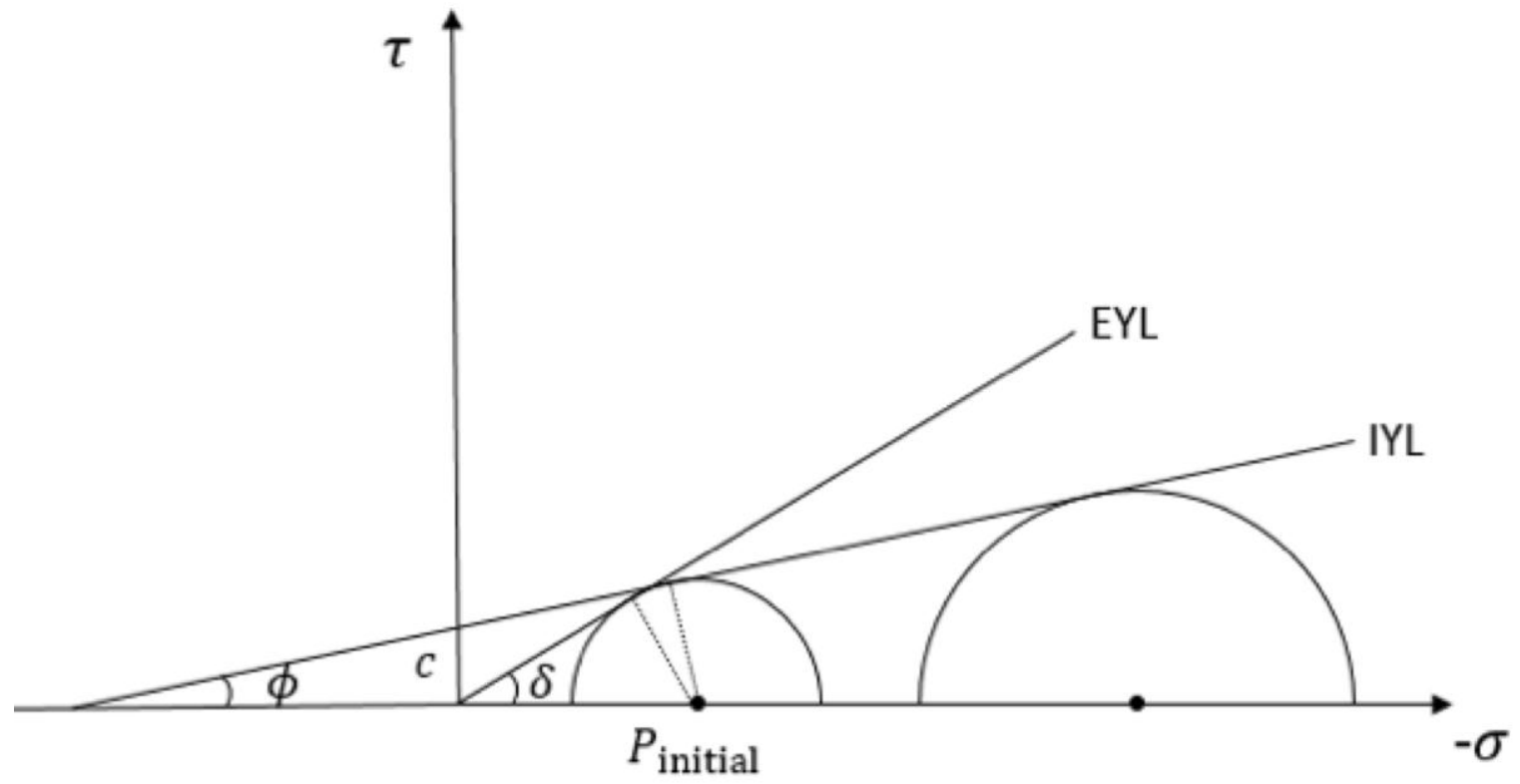



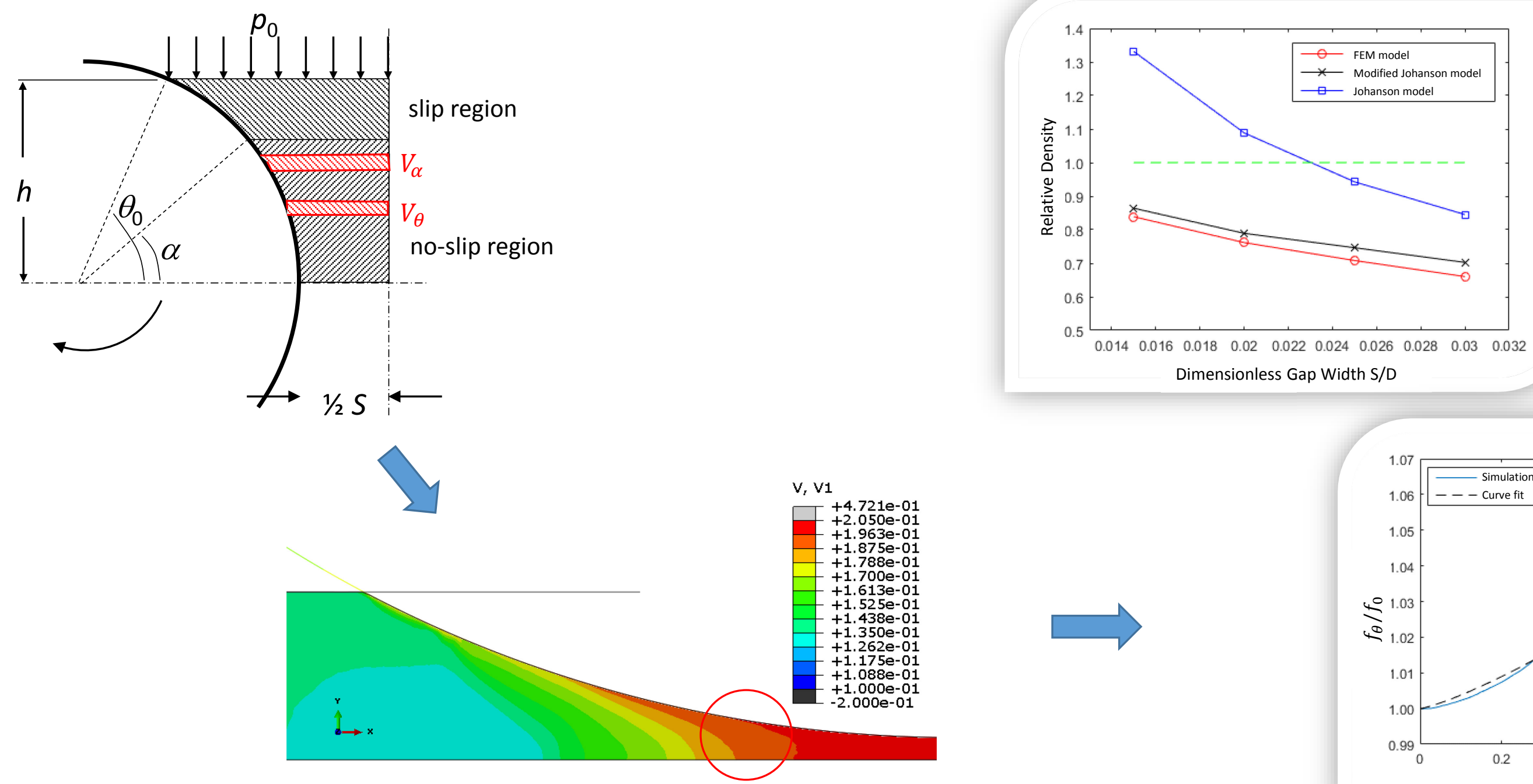

$\rho_{\theta} V_{\theta}=f_{\theta} \rho_{\alpha} V_{\alpha}$

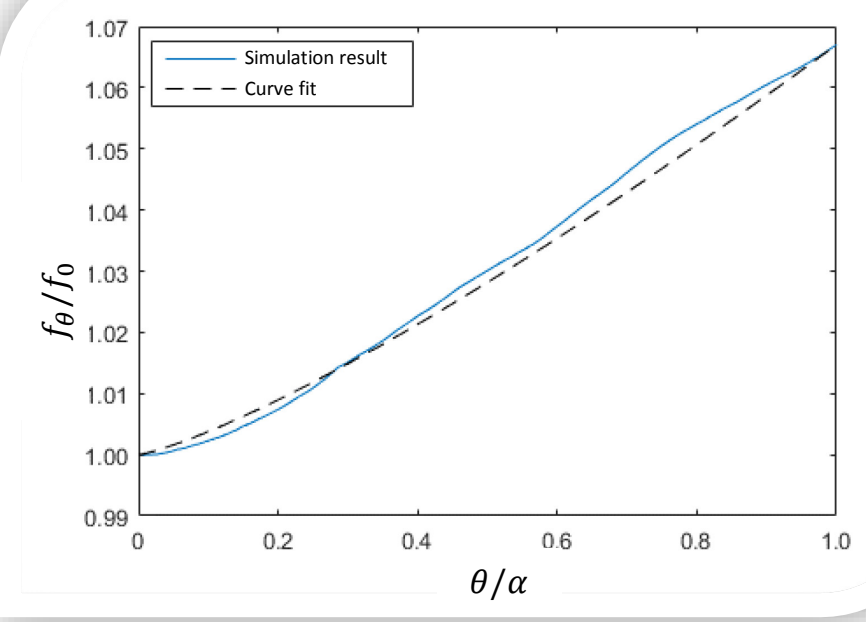

